\title{
A Rare Case Report of Crigler Najjar Syndrome Type II
}

Eusha Abdul Raffay ${ }^{1}$, Ayesha Liaqat ${ }^{1}$, Maria Khan ${ }^{2}$, Ali I. Awan ${ }^{3}$, Bakhat Mand ${ }^{1}$

1. Internal Medicine, Services Institute of Medical Sciences, Lahore, PAK 2. Internal Medicine, King Edward Medical University/Mayo Hospital, Lahore, PAK 3. Psychiatry and Behavioral Sciences, King Edward Medical University/Mayo Hospital, Lahore, PAK

Corresponding author: Eusha Abdul Raffay, dr.eusharaffay@gmail.com

\begin{abstract}
Crigler-Najjar syndrome is an inborn error of metabolism caused by a point mutation in one of the five exons of UGT1A1 gene, the product of which is responsible for elimination of bilirubin via bile. A number of hyperbilirubinemia disorders similar to Crigler-Najjar syndrome are reported, but they differ in their level of unconjugated bilirubin and responses to the treatment. Here we report a 14 -year-old male patient admitted to hospital with the complaint of vomiting and frequent tonsillitis. Further examination revealed that he was jaundiced since birth and had a family history of similar disorder. This report is about an extremely rare case of Crigler-Najjar syndrome type II and also management of the condition to provide the patient with a healthy lifestyle.
\end{abstract}

Categories: Genetics, Internal Medicine, Gastroenterology

Keywords: crigler-najjar syndrome, phenobarbital, ugt1a1 gene, hyperbilirubinemia, unconjugated bilirubin

\section{Introduction}

Crigler-Najjar syndrome type II (CN-II) is a rare genetic disorder caused by mutations in the UGT1A1 gene. The mode of inheritance of this disorder is autosomal recessive. Mutations in the same gene could alternatively cause other disorders like Crigler-Najjar Syndrome type I and Gilbert syndrome. The disorder is characterized by hyperbilirubinemia. Bilirubin is normally an end product of erythrocyte breakdown and mutation in UGT1A1 causes dysfunction of bilirubin-UDP-glucuronosyltransferase. The bilirubin-UDPglucuronosyltransferase enzyme is involved in detoxification of bilirubin by conjugating it with glucuronic acid [1,2]. Malfunctioning bilirubin-UDP-glucuronosyltransferase prevents conjugation of bilirubin with glucuronic acid, leading to elevated plasma level of unconjugated bilirubin exhibiting the symptoms of jaundice [3]. The incidence of the disorder is 1 in $750,000-1,000,000$ people [4].

Review began 10/13/2020 Review ended 01/11/2021 Published 01/12/2021

\section{(๑) Copyright 2021}

Abdul Raffay et al. This is an open access article distributed under the terms of the Creative Commons Attribution License CC-BY 4.0., which permits unrestricted use, distribution, and reproduction in any medium, provided the original author and source are credited.

\section{Case Presentation}

A 14-year-old boy was admitted to the hospital because of severe vomiting and frequent tonsillitis. On examination, yellowing of sclera and skin was observed. His father told that the boy was jaundiced since birth. On further inquiry, his father mentioned that his paternal cousin (18 years old) and grandparents of both affected individuals have the same condition. In addition, the parents of the patient were first cousins. Both the patients had normal development and were good at learning. Keeping in view the history, signs and symptoms, further clinical examination was performed.

The patient had a normal hematological report. Ultrasonography indicated no visceromegaly. Total serum bilirubin was $16.1 \mathrm{mg} / \mathrm{dL}$ (unconjugated bilirubin $15.6 \mathrm{mg} / \mathrm{dL}$ ), aspartate aminotransferase $18 \mathrm{U} / \mathrm{L}$ (normal $<38 \mathrm{U} / \mathrm{L}$ ), alanine aminotransferase $19 \mathrm{U} / \mathrm{L}$ (normal <40 U/L), Y-glutamyl transpeptidase $14 \mathrm{U} / \mathrm{L}$ (normal 49 $\mathrm{U} / \mathrm{L}$ ), alkaline phosphatase $16.4 \mathrm{U} / \mathrm{L}$ (normal $<500 \mathrm{U} / \mathrm{L}$ ). The patient was negative for hepatitis B surface antigen (HBsAg) and anti-hepatitis $\mathrm{C}$ virus (HCV) antibody. Since the ultrasonography indicated normal liver with no biliary obstruction and raised serum bilirubin with liver function tests (LFTs) in the physiological range, the patient was suspected of CN-II and Gilbert syndrome. Crigler-Najjar syndrome type II was clearly suspected because the patient had high serum bilirubin. First, treatment was given for his complaint against vomiting and tonsillitis.

On the grounds of patient history, clinical examination and laboratory findings, CN-II was diagnosed. After successful clinical diagnosis, the target was to lower the level of unconjugated bilirubin in the patient. A 30 mg dose of phenobarbital was started twice a day. Vitamin D supplement was also recommended. His LFTs were repeated after regular intervals and luckily the unconjugated bilirubin level reduced to $9.5 \mathrm{mg} / \mathrm{dL}$ within one month. The patient was advised to see the physician again after four weeks to evaluate the outcome of treatment with phenobarbital and was discharged after proper genetic and lifestyle counselling.

\section{Discussion}

Crigler-Najjar syndrome is an inborn error of metabolism and also a rare genetic disorder. It is important to 
distinguish between subtypes of $\mathrm{CN}$ for which response to phenobarbital, molecular and functional characterizations are considered [5]. Crigler-Najjar type II syndrome is comparatively a benign disorder that is usually observed in infants or in early childhood. CN-I is found in newborns at or soon after birth, and can lead to death, if untreated, as a consequence of kernicterus. The serum bilirubin levels in patients with CN-II range between 10 and $20 \mathrm{mg} / \mathrm{dL}$ (175 and $350 \mathrm{mmol} / \mathrm{L}$ ) with infrequent kernicterus [3]. Gilbert syndrome, Rotor syndrome, and Dubin-Johnson syndrome are other rare inborn errors of metabolism characterized by hyperbilirubinemia, but they differ either in their response to phenobarbital, level of bilirubin or the pathway through which the level of bilirubin elevates.

Crigler-Najjar syndrome could be diagnosed easily within a few days after birth as the infant is jaundiced. Further, for the confirmation of diagnosis, clinical evaluation could be extended to specialized testing, characteristic findings and probing the family history. For example, if an infant has elevated level of unconjugated serum bilirubin without hemolysis, bile glucuronides and bilirubin in urine.

Molecular testing could be performed to confirm the presence of $\mathrm{CN}$-II which will detect the pathogenic variant in the UGT1A1 gene known to cause the disorder. Unfortunately, the facility is present in few centers in Pakistan, which is why a genetic test was not performed. The only available tool for diagnosis was level of unconjugated bilirubin and family history, which was evidence of CN-II. This case is one of a few cases of $\mathrm{CN}-\mathrm{II}$ reported from Pakistan in which the affected individuals are cousins and born to parents who are also first cousins.

Currently, research on inborn errors of metabolism is a hot topic. Scientists are destined to develop enzyme replacement therapies that may complement the deficient or missing enzyme. Research is also ongoing on whether liver transplantation could help patients in this regard, because although the liver remains normal in these patients, transplantation could correct the malfunctioning hepatocytes and provide normal UGT1A1 enzyme [4].

\section{Conclusions}

Crigler-Najjar type II is a rare genetic disorder, the diagnosis of which poses a great challenge to the physician. However, with thorough history, especially the family history and physical findings supported by laboratory work-up, the condition can be diagnosed. Further genetic testing is required for definitive diagnosis. Management involves a multi-faceted approach which includes counselling regarding life-long dietary modification, ensuring adequate hydration, avoidance of triggers like stress, and life-long phenobarbital therapy. Genetic counselling, especially regarding consanguinity, is an important part of management along with regular follow-up. Currently, the available treatment strategies can stop the development of complications; however, therapies aimed at specific gene mutations need to be developed.

\section{Additional Information \\ Disclosures}

Human subjects: Consent was obtained or waived by all participants in this study. Conflicts of interest: In compliance with the ICMJE uniform disclosure form, all authors declare the following: Payment/services info: All authors have declared that no financial support was received from any organization for the submitted work. Financial relationships: All authors have declared that they have no financial relationships at present or within the previous three years with any organizations that might have an interest in the submitted work. Other relationships: All authors have declared that there are no other relationships or activities that could appear to have influenced the submitted work.

\section{References}

1. Sampietro M, Iolascon A: Molecular pathology of Crigler-Najjar type I and II and Gilbert's syndromes . Haematologica. 1999, 84:150-157.

2. Kumar P, Sasmal G, Gupta S, Saxena R, Kohli S: Crigler Najjar Syndrome Type 2 (CNS Type 2): an unwonted cause of jaundice in adults. J Clin Diagn Res. 2017, 11:OD05-OD06.

3. Liaqat A, Shahid A, Attiq H, Ameer A, Imran M: Crigler-Najjar Syndrome Type II diagnosed in a patient with jaundice since birth. J Coll Physicians Surg Pak. 2018, 28:806-808.

4. Crigler Najjar Syndrome. (2020). http://rarediseases.org/rare-diseases/crigler-najjar-syndrome.

5. Sinha R, S Dalal, Sodhi K: Differentiating Gilbert Syndrome from Crigler Najjar Syndrome Type 2 by phenobarbitone test. J Nepal Paed Soc. 2015, 35:82-84. 10.3126/jnps.v35i1.10620 